\title{
Association of Gestational Diabetes Mellitus Diagnosed using the IADPSG and the POGS 75 gram Oral Glucose Tolerance Test Cut-off Values with Adverse Perinatal Outcomes in the Philippine General Hospital
}

\author{
Hannah Urbanozo and Iris Thiele Isip-Tan \\ Section of Endocrinology, Diabetes and Metabolism, Department of Medicine \\ University of the Philippines-Philippine General Hospital Manila
}

\begin{abstract}
Objective. To determine the association of adverse perinatal outcomes among women with gestational diabetes mellitus (GDM) according to the International Association of Diabetes and Pregnancy Study Groups (IADPSG) and the Philippine Obstetrical and Gynecological Society (POGS) diagnostic cut-offs for $75 \mathrm{~g}$ oral glucose tolerance test (OGTT).

Methodology. A review of deliveries from September to December 2013 at the charity services of the Philippine General Hospital (PGH) looking at $75 \mathrm{~g}$ OGTT results and perinatal outcomes was done. The association between GDM and perinatal outcomes were estimated and tested using logistic regression analysis. The diagnostic accuracy between the POGS and the IADPSG criteria was tested by comparing their areas under the curve (AUC).

Results. A total of 236 deliveries were included. The GDM group had a significantly increased risk for primary Caesarean section (CS) $(\mathrm{OR}=1.79,95 \% \mathrm{Cl}: 1.02-3.16, p=0.041)$ and infant admission to the Neonatal Intensive Care Unit (NICU) (OR=2.66, 95\% Cl: $1.3-5.44, p=0.007)$. Per category of glycemia, a 1-hour OGTT value $\geq 180 \mathrm{mg} / \mathrm{dL}$ was associated with an increased risk for primary CS (OR=1.968, 95\% Cl: 1.08-3.55); a fasting blood sugar (FBS) $\geq 92$ $\mathrm{mg} / \mathrm{dL}$ with increased risk for large for gestational age (LGA) infants (OR=20.97, 95\% Cl 2.27-192.97); and elevated FBS, 1-hour and 2-hour OGTT blood glucose values with increased risk for infant admission to the NICU (OR=2.18, $\mathrm{OR}=2.39, \mathrm{OR}=2.34$, respectively). There was no significant difference in outcomes between women diagnosed using the IADPSG and POGS criteria $(n=104)$ and those diagnosed with the IADPSG criteria only $(n=90)$.

Conclusion. The currently used cut-off values in diagnosing GDM was associated with increased risk for primary CS and infant admission to NICU. No significant difference in outcomes was found between the group of women that included those diagnosed with the more stringent POGS criteria from the group that excluded them, implying adequacy of the IADPSG thresholds for local use.
\end{abstract}

Keywords: gestational diabetes mellitus, pregnancy outcome, oral glucose tolerance test

\section{INTRODUCTION}

Carbohydrate intolerance in pregnancy and its postulated adverse effects affecting mother and offspring in terms of immediate perinatal and later long-term events have been well-studied and documented since the early $20^{\text {th }}$ century. ${ }^{1}$ The burden of disease is such that it affects $14 \%$ of pregnancies in the Philippines, and about 2 to $10 \%$ in the United States. ${ }^{2,3}$

Specific levels of glycemia harmful to the feto-maternal environment have been studied and scrutinized. It is generally accepted that maternal perigravid blood sugar levels less severe than that found in diabetes mellitus in the non-pregnant adult are associated with adverse

\section{e-ISSN 2308-118X}

Printed in the Philippines

Copyright $(0) 2014$ by the JAFES

Received May 9, 2014. Accepted May 30, 2014

http://dx.doi.org/10.15605/jafes.029.02.09 perinatal outcomes. ${ }^{4,5}$ Adverse maternal outcomes include development of overt diabetes mellitus postpartum, and increased incidence of primary CS, preeclampsia and preterm delivery. 1,3,7 Adverse outcomes in the offspring include increased birth weight, neonatal hypoglycemia, childhood metabolic syndrome and obesity., 2,-10

Locally and internationally, the current prevalent practice for diagnosing GDM entails the use of the $75 \mathrm{~g}$ OGTT. Internationally endorsed cut-offs for the diagnosis of GDM include: (1) the consensus statement of the American Diabetes Association (ADA) and the International Association of Diabetes and Pregnancy Study Groups (IADPSG), (2) the consensus statement of the World Health Organization (WHO), and (3) the consensus
Corresponding author: Hannah C. Urbanozo, MD

Section of Endocrinology, Diabetes and Metabolism

University of the Philippines-Philippine General Hospital

Taft Avenue, Ermita

1000 Manila, Philippines

Tel. No.: +632-554-8400 local 3230

E-mail: hannahcumd@gmail.com 
statement of the American College of Obstetrics and Gynecology (ACOG) (Table 1).

Table 1. International consensus cut-offs for diagnosing gestational diabetes mellitus

\begin{tabular}{|c|c|c|c|}
\hline & $\begin{array}{l}\text { ADA }^{\mathrm{a}} \text { 2012/ } \\
\text { IADPSG }^{\mathrm{b}}\end{array}$ & $\mathrm{ACOG}^{\mathrm{C}}$ & $\mathrm{WHO}^{\mathrm{d}}$ \\
\hline & $75 \mathrm{~g}$ OGTT & $100 \mathrm{~g}$ OGTT & $75 \mathrm{~g}$ OGTT \\
\hline Fasting glucose, $\mathrm{mg} / \mathrm{dL}$ & $>92$ & $>95$ & $>126$ \\
\hline 1-hour glucose, mg/dL & $\geq 180$ & $\geq 180$ & - \\
\hline 2-hour glucose, $\mathrm{mg} / \mathrm{dL}$ & $>153$ & $>155$ & $>140$ \\
\hline 3-hour glucose, $\mathrm{mg} / \mathrm{dL}$ & - & $>140$ & - \\
\hline Criteria for diagnosis & At least 1 & 2 or more & At least 1 \\
\hline $\begin{array}{l}{ }^{\mathrm{a}} \mathrm{ADA}, \text { American Diabete } \\
\text { bIADPSG, International } \\
\text { Groups } \\
{ }^{\mathrm{C}} \mathrm{ACOG} \text {, American Colle } \\
{ }^{\mathrm{W}} \mathrm{WHO} \text {, World Health Or }\end{array}$ & $\begin{array}{l}\text { Association } \\
\text { sociation of } D\end{array}$ & d Gynecolo & רcy Study \\
\hline
\end{tabular}

The widely used IADPSG criteria was formulated with evidence from the Hyperglycemia Adverse Pregnancy Outcomes (HAPO) trial, where maternal glucose levels below those diagnostic of diabetes were found to have strong associations with increased birth weight and increased cord blood serum C-peptide levels, and weak associations with primary CS and neonatal hypoglycemia. ${ }^{7}$

Locally, we have criteria endorsed by two groups. The first is by the UNITE for Diabetes Philippines, which endorsed the IADPSG criteria; the second is from the Philippine Obstetrical and Gynecological Society (POGS). The POGS endorsed a cut-off for the 2-hour OGTT blood glucose of $140 \mathrm{mg} / \mathrm{dL}$, derived from the WHO guideline instead of the IADPSG (Table 2). ${ }^{11,12}$ The lack of uniformity of cut-offs translates clinically into opposing diagnoses for a single patient should she happen to have a 2-hour OGTT glucose value $>140 \mathrm{mg} / \mathrm{dL}$ but $<153 \mathrm{mg} / \mathrm{dL}$. This poses a challenge to the formulation of a consolidated guideline for managing Filipino women with GDM.

Table 2. Cut-off values for diagnosing gestational diabetes mellitus in current local use

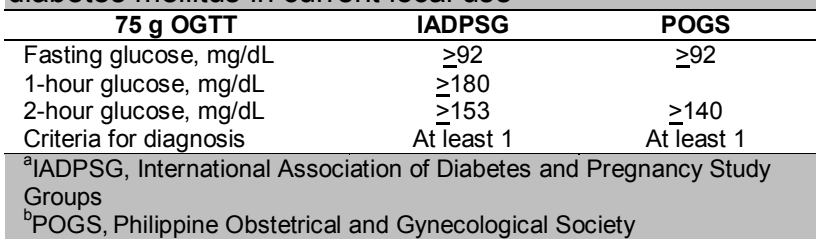

The outright adaptation of foreign diagnostic cut-offs raises some important concerns. The studies which eventually formed the bases for these guidelines have commonly combined all Asians into a single ethnic group regardless of country of origin. In HAPO, study participants self-reported ethnicity as $48.3 \%$ white, $11.6 \%$ black, $8.5 \%$ Hispanic and 29\% "consider themselves" Oriental. Hispanicega ${ }^{13}$ noted that there was a diverse rate of GDM incidence among Asian groups. ${ }^{13}$ This led to the theory that there may also be differences in pregnancy outcomes among these groups. Silva and associates found that neonates born to native-Hawaiian/Pacific-Islander mothers were more likely to have hypoglycemia, while those born to Native-Hawaiian/Pacific-Islander and Filipino mothers were more likely to have hyperbilirubinemia compared to other ethnic groups.
Native-Hawaiian/Pacific-Islander women were also more likely to have neonates with macrosomia than women from the other ethnic groups. ${ }^{14}$

A study to determine the association of GDM diagnosed using the IADPSG or POGS criteria with perinatal outcomes in the Philippine setting and a comparison of these two criteria in predicting adverse perinatal outcomes will be helpful in formulating a unified local guideline for the diagnosis of GDM among Filipino mothers.

\section{METHODOLOGY}

A chart review of deliveries at the charity obstetric wards of the Philippine General Hospital from September to December 2013 was done. Patients included were those who were aged 18 years old and above; with singleton pregnancy; with available complete obstetric record, hospital chart and $75 \mathrm{~g}$ OGTT results. Patients were excluded if they had no available $75 \mathrm{~g}$ OGTT, underwent $100 \mathrm{~g}$ instead of $75 \mathrm{~g}$ OGTT, had previously diagnosed DM, with overt DM, or with twin or multiple pregnancy (Figure 1). The study protocol was submitted to the PGH Ethical Review Board (ERB) for ethics review and approval. Implementation of the study began upon receipt of approval from the ERB. All patient information was anonymized and kept confidential.

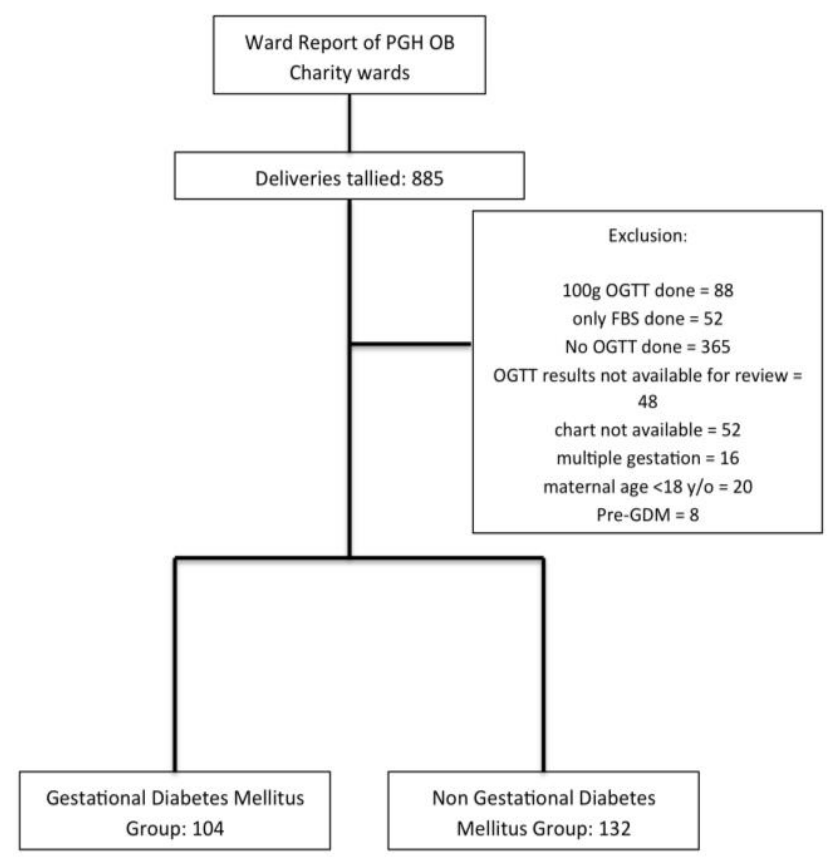

Figure 1. Screening and inclusion process

Subjects were then categorized into those without GDM and those with GDM based on the IADPSG or the POGS criteria. Maternal outcomes included primary CS, preterm delivery and preeclampsia. Infant outcomes included LGA, defined as birth weight above the $90^{\text {th }}$ percentile for gestational age using the WHO birth weight for pediatric gestational aging; birth injury; congenital anomaly; fetal death-in-utero (FDU); admission to the NICU; and 
neonatal hypoglycemia, defined as having a medical record that contained a notation of neonatal hypoglycemia, with symptoms and/or treatment with glucose infusion, or a laboratory report of a glucose value $<30.6 \mathrm{mg} / \mathrm{dL}$ in the first 24 hours, and/or $\leq 45 \mathrm{mg} / \mathrm{dL}$ after the first 24 hours. ${ }^{15,16}$

Using Power Analysis and Sample Size 2008 software, a minimum sample size requirement of 183 subjects was computed using the parameters for logistic regression analysis: alpha $=0.05$, power $(1-\beta)=80 \%$, P0 (proportion of large for gestational age among women without GDM) $=0.012, \mathrm{P} 1$ (proportion of large for gestational age among women with GDM) $=0.12$. The outcome of LGA was determined to have the smallest effect of interest and was chosen for sample size calculation. With the exception of alpha and power levels, which were set by the researcher, all other parameters were taken from the literature. ${ }^{8}$

Data were encoded in MS Excel and analyzed in Stata SE version 12. Descriptive statistics included mean and standard deviation for quantitative variables, and frequency and percent distribution for qualitative variables. To compare the homogeneity of the GDM and non-GDM groups across different socio-demographic and clinical variables, independent t-test and Fisher distribution for quantitative and qualitative variables, respectively. The association between GDM and perinatal outcomes were estimated and tested using logistic regression analysis. Lastly, the area under the curve (AUC) between the IADPSG and the POGS in predicting perinatal outcomes were compared and tested. The level of significance $(\alpha)$ was set at 0.05 .

\section{RESULTS AND DISCUSSION}

A total of 1,183 charity deliveries were recorded for September to December 2013. Of these, 885 charts were available for review. About $26 \%$ had OGTT values available for review. Many deliveries were from women who had not undergone appropriate pre-conception care, including the lack of an OGTT, overall, 236 charts met the inclusion criteria and were included in the study, 104 were deliveries from women diagnosed with GDM and 132 from those without GDM.

Comparison of baseline characteristics revealed that patients with GDM were older $(p=0.019)$ and had higher pre-pregnancy weight $(p=0.012)$. This was similar to the observations in another study, where advancing age and higher pre-pregnancy body mass index (BMI) were correlated with an increased risk for gestational diabetes (Table 3). ${ }^{8}$ No significant difference was found between the two groups in terms of gravidity, parity, previous diagnosis of gestational hypertension and previous diagnosis of GDM. A history of GDM was only found among patients who were presently diagnosed with GDM.
Table 3. Maternal antepartum characteristics

\begin{tabular}{|c|c|c|c|}
\hline Characteristics & $\begin{array}{c}\text { GDM } \\
\mathrm{n}=104\end{array}$ & $\begin{array}{c}\text { Non-GDM } \\
n=132\end{array}$ & $p$-value \\
\hline Age (SD), yr & $32.28(6.05)$ & $30.27(6.86)$ & 0.0192 \\
\hline Gravidity (SD) & $2.79(1.63)$ & $2.80(1.82)$ & 0.9880 \\
\hline Parity (SD) & $1.44(1.38)$ & $1.56(1.70)$ & 0.5381 \\
\hline $\begin{array}{l}\text { With previous diagnosis } \\
\text { of GDM, \% }\end{array}$ & 2.9 & 0 & 0.0840 \\
\hline $\begin{array}{l}\text { Pre-pregnancy weight } \\
\text { (SD), kg }\end{array}$ & $54.47(8.38)$ & $51.13(9.76)$ & 0.0120 \\
\hline $\begin{array}{l}\text { Pre-pregnancy BMI }{ }^{\mathrm{a}} \text { (SD), } \\
\mathrm{kg} / \mathrm{m}^{2}\end{array}$ & $22.85(9.30)$ & $21.73(3.68)$ & 0.2485 \\
\hline $\begin{array}{l}\text { Mean arterial pressure } \\
\text { (SD), } \mathrm{mmHg} \\
75 \mathrm{~g} \text { OGTT } \\
\text { b } \mathrm{mg} / \mathrm{dL}\end{array}$ & $94.49(19.62)$ & $92.44(12.85)$ & 0.3583 \\
\hline Fasting blood glucose (SD) & $86.40(20.88)$ & $64.80(9.90)$ & $<0.0001$ \\
\hline $\begin{array}{l}\text { 1-hour post-challenge } \\
\text { blood glucose ( SD) }\end{array}$ & $190.08(31.50)$ & $120.42(24.12)$ & $<0.0001$ \\
\hline $\begin{array}{l}\text { 2-hour post-challenge } \\
\text { blood glucose (SD) }\end{array}$ & $155.52(30.06)$ & $101.52(17.82)$ & $<0.0001$ \\
\hline Any prenatal smoking, \% & 0 & 2.27 & 0.2570 \\
\hline $\begin{array}{l}\text { With Family History of } \\
\text { DM, \% }\end{array}$ & 25.96 & 18.18 & 0.1560 \\
\hline $\begin{array}{l}\text { Obstetric History, \% } \\
\text { Previous LGA }{ }^{c} \text { infant }\end{array}$ & 0.96 & 0 & 0.4410 \\
\hline $\begin{array}{l}\text { Congenital malformation in } \\
\text { previous pregnancy }\end{array}$ & 0 & 0 & - \\
\hline $\begin{array}{l}\text { Previous history of } \\
\text { gestational hypertension }\end{array}$ & 0.96 & 0.76 & 1.0000 \\
\hline $\begin{array}{l}\text { a BMI, body mass index } \\
\text { bOGT, oral glucose tole } \\
\text { c } \mathrm{LGA} \text {, large for gestatione }\end{array}$ & test & & \\
\hline
\end{tabular}

Table 7 shows the association between GDM with perinatal outcomes. There was a significant increase in the risk of primary CS in women with GDM (OR=1.79, 95\% CI: 1.02-3.16, $p=0.041)$ and infant admission to the NICU (OR=2.66, 95\% CI: 1.3 -5.44), $p=0.007)$. The most common indication for admission to the NICU was congenital anomaly for the GDM group and neonatal sepsis for the non-GDM group (Table 6). For primary CS, on other hand, "non-reassuring fetal status" was the most commonly cited indication among GDM mothers, while malpresentation was the most common among non-GDM mothers (Table 4). A trend for higher risk of LGA, preeclampsia, preterm delivery and congenital anomalies was observed in those with GDM, but these did not reach statistical significance.

\begin{tabular}{lccc} 
Table 4. Indications for primary & \multicolumn{3}{c}{ Caesarean section } \\
\hline & $\begin{array}{ccc}\text { GDM } \\
\mathbf{n}=\mathbf{3 8}\end{array}$ & $\begin{array}{c}\text { Non-GDM } \\
\mathbf{n}=\mathbf{2 4}\end{array}$ & Total \\
\hline
\end{tabular}

\begin{tabular}{l}
\hline Elective \\
Mild pre-eclampsia \\
Elderly primigravid \\
Congenital anomalies \\
Low placenta \\
Post-term \\
LGA $^{\mathrm{a}}$ \\
Oligohydramnios \\
CPD by pelvimetry \\
Maternal restrictive lung disease \\
Concomitant myoma uteri \\
GDM \\
Malpresentation \\
Grandmultipara \\
No indication written \\
Emergent \\
Preterm labor in breech \\
Non-reassuring fetal status \\
Maternal decompensation \\
Dysfunctional labor \\
Placental abruption \\
Preterm premature rupture of \\
membranes \\
No indication written
\end{tabular}

$\begin{array}{ccc}1 & - & 1 \\ 1 & - & 1 \\ 5 & 1 & 6 \\ 5 & 1 & 6 \\ 1 & 1 & 2 \\ 1 & - & 1 \\ 1 & - & 1 \\ 1 & 1 & 2 \\ 1 & - & 1 \\ 1 & 1 & 2 \\ 3 & - & 3 \\ - & 7 & 7 \\ - & 1 & 1 \\ 1 & - & 1 \\ & & \\ 1 & - & 1 \\ 8 & 5 & 13 \\ 2 & - & 2 \\ 4 & 3 & 7 \\ 1 & - & 1 \\ - & 1 & 1 \\ - & 2 & 2\end{array}$

${ }^{\mathrm{a}} \mathrm{LGA}$, large for gestational age 
Neonatal hypoglycemia was documented in 3 deliveries, all from mothers with GDM. One infant birth injury was noted: a subgaleal hematoma following vaginal delivery with vacuum extraction to a non-GDM mother due to dysfunctional labor. No incidence of FDU was noted. These outcomes were not analyzed due to their relatively small frequency. Independent T-test showed that the APGAR Scores and birth weights did not significantly differ between the two groups (Table 5).

Table 5. Clinical profile of neonates

\begin{tabular}{lccc}
\hline & GDM & Non-GDM & p-value \\
\hline $\begin{array}{l}\text { APGAR Score } \\
\text { mean (SD) }\end{array}$ & & & \\
1- minute & $8.61(0.988)$ & $8.64(1.17)$ & 0.831 \\
5 -minute & $8.92(0.330)$ & $8.88(0.56)$ & 0.494 \\
$\begin{array}{l}\text { Birth weight } \\
\text { mean (SD), kg }\end{array}$ & $2642.50(704.730)$ & $2721.89(564.40)$ & 0.350 \\
\hline
\end{tabular}

Our analysis showed that for each category of glycemia, the risk for primary CS significantly increased with 1-hour OGTT levels $\geq 180 \mathrm{mg} / \mathrm{dL}$ (OR=1.968, 95\% CI: 1.08-3.55), $p=0.025$ ) (Table 6). The risk for LGA also increased significantly with FBS $\geq 92 \mathrm{mg} / \mathrm{dL}$ (OR=20.97, 95\% CI: $2.27-$ 192.97), $p=0.007)$. Odds ratios for infant admission to the NICU were also significantly increased for all 3 categories of glycemia.

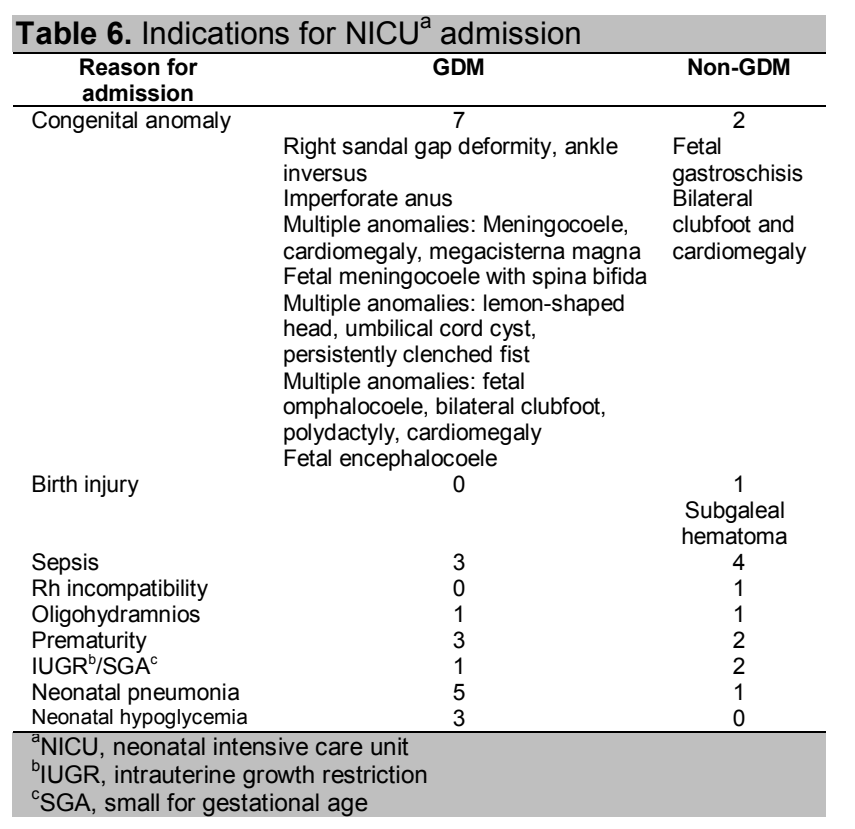

Of the women with GDM, a small number (3\%) was managed expectantly, the majority with diet, and the rest with insulin.

Comparison of the frequencies of outcomes between the GDM women that included the POGS-criteria diagnosed women $(n=104)$ and the group that excluded the POGScriteria diagnosed women $(n=90)$ using the two-sample Ttest found no significant difference in both glycemic levels as well as all outcomes (Table 9).

Table 7. Odds ratios for maternal and infant perinatal outcomes

\begin{tabular}{|c|c|c|c|c|}
\hline Outcomes & $\begin{array}{c}\text { With } \\
\text { GDM } \\
(n=104)\end{array}$ & $\begin{array}{c}\text { Without } \\
\text { GDM } \\
(n=132)\end{array}$ & Odds ratio & $p$-value \\
\hline \multicolumn{5}{|l|}{ Maternal } \\
\hline Primary $\mathrm{CS}^{\mathrm{a}}$ & 38 & 32 & $1.79(1.02,3.16)$ & 0.041 \\
\hline Pre-eclampsia & 11 & 9 & $1.16(0.64,4.06)$ & 0.307 \\
\hline Preterm delivery & 23 & 19 & $1.68(0.86,3.30)$ & 0.069 \\
\hline \multicolumn{5}{|l|}{ Fetal } \\
\hline LGA $^{b}$ birth weight & 4 & 1 & $5.24(0.57,47.60)$ & 0.141 \\
\hline Neonatal hypoglycemia & 3 & 0 & - & - \\
\hline Birth injuries & 0 & 1 & - & - \\
\hline$F D U^{c}$ & 0 & 0 & - & - \\
\hline Admission to $\mathrm{NICU}^{\mathrm{d}}$ & 25 & 14 & $2.66(1.3,5.44)$ & 0.007 \\
\hline Congenital anomaly & 7 & 4 & $2.30(0.65,8.11)$ & 0.192 \\
\hline
\end{tabular}

Table 8. Comparison of ROC Area of POGS ${ }^{\mathrm{a}}$-diagnosed and IADPSG ${ }^{b}$-diagnosed GDM mothers

\begin{tabular}{|c|c|c|}
\hline \multirow[t]{2}{*}{ Outcomes } & \multicolumn{2}{|c|}{ ROC Area } \\
\hline & $\begin{array}{c}\text { POGS }^{a} \\
(n=104)\end{array}$ & $\begin{array}{c}\text { IADPSG }^{0} \\
(\mathrm{n}=90)\end{array}$ \\
\hline $\begin{array}{l}\text { Maternal } \\
\text { Primary } \mathrm{CS}^{c} \\
\text { Preterm delivery }\end{array}$ & $\begin{array}{l}0.5607 \\
0.5519\end{array}$ & $\begin{array}{l}0.5803 \\
0.5600\end{array}$ \\
\hline $\begin{array}{l}\text { Infant } \\
\text { LGA }^{d} \text { birth weight } \\
\text { Neonatal hypoglycemia } \\
\text { Birth injuries } \\
\text { Congenital anomaly } \\
\text { Admission to } \mathrm{NICU}^{\mathrm{e}}\end{array}$ & $\begin{array}{c}0.7333 \\
0.6638 \\
- \\
- \\
0.6061 \\
0.6016\end{array}$ & $\begin{array}{c}0.6745 \\
0.5379 \\
- \\
- \\
0.6028 \\
0.5756\end{array}$ \\
\hline $\begin{array}{l}{ }^{a} \text { POGS, Philippine Obste } \\
{ }^{b} \text { IADPSG, International } \\
\text { Groups } \\
{ }^{\mathrm{c}} \mathrm{CS} \text {, Caesarean section } \\
\text { d LGA, large for gestation } \\
{ }^{\mathrm{e}} \mathrm{NICU} \text {, neonatal intensiv }\end{array}$ & $\begin{array}{l}\text { Gynecolo } \\
\text { on of Diabe }\end{array}$ & Inancy Study \\
\hline
\end{tabular}

Table 9. Odds ratios for associations between maternal glycemia by OGTT parameter and perinatal outcomes

\begin{tabular}{|c|c|c|c|c|c|c|}
\hline \multirow[t]{2}{*}{ Outcomes } & \multicolumn{2}{|c|}{$\begin{array}{c}\text { Fasting glucose } \\
\geq 92 \mathrm{mg} / \mathrm{dL}\end{array}$} & \multicolumn{2}{|c|}{$\begin{array}{c}\text { 1-hour post-OGTT glucose } \\
\geq 180 \mathrm{mg} / \mathrm{dL}\end{array}$} & \multicolumn{2}{|c|}{$\begin{array}{c}2 \text { hour post-OGTT glucose } \\
>140 \mathrm{mg} / \mathrm{dL}\end{array}$} \\
\hline & $\begin{array}{l}\text { Odds ratio } \\
(95 \% \mathrm{Cl})\end{array}$ & $p$-value & $\begin{array}{l}\text { Odds ratio } \\
(95 \% \mathrm{Cl})\end{array}$ & $p$-value & $\begin{array}{l}\text { Odds ratio } \\
(95 \% \mathrm{Cl})\end{array}$ & $p$-value \\
\hline \multicolumn{7}{|l|}{ Maternal } \\
\hline Primary CS & $0.977(0.46,2.04)$ & 0.952 & $1.968(1.08,3.55)$ & $0.025^{*}$ & $1.691(1.03,3.48)$ & 0.074 \\
\hline Pre-eclampsia & $1.660(0.56,4.87)$ & 0.351 & $2.070(0.82,5.2)$ & 0.123 & $1.550(0.78,3.08)$ & 0.201 \\
\hline Preterm delivery & $1.939(0.88,4.27)$ & 0.100 & $1.232(0.60,2.51)$ & 0.566 & $1.610(0.77,3.33)$ & 0.778 \\
\hline \multicolumn{7}{|l|}{ Infant } \\
\hline LGA $^{a}$ birth weight & $20.970(2.27,192.97)$ & $0.007^{*}$ & $1.590(0.26,9.77)$ & 0.612 & $7.990(0.87,72.8)$ & 0.065 \\
\hline Neonatal hypoglycemia & - & - & - & - & - & - \\
\hline Birth injuries & - & - & - & - & - & - \\
\hline Congenital anomaly & $1.059(0.22,5.09)$ & 0.942 & $2.051(0.60,6.95)$ & 0.249 & $2.400(0.70,8.11)$ & 0.159 \\
\hline Admission to NICU & $2.180(0.98,4.85)$ & $0.050^{*}$ & $2.390(1.18,4.83)$ & $0.015^{*}$ & $2.340(1.16,4.71)$ & $0.016^{*}$ \\
\hline
\end{tabular}


For the outcome of LGA, the area under the curve of the IADPSG criteria is 0.6745 , while that of the POGS criteria was 0.7333 (Figure 2). There was no significant difference between the two AUCs ( $p=0.7958)$. The same finding was seen for the outcome of primary CS, where the IADPSG criteria had an AUC of 0.5803 and the POGS had an AUC of 0.5607 ( $p=0.819879$ ) (Figure 3).

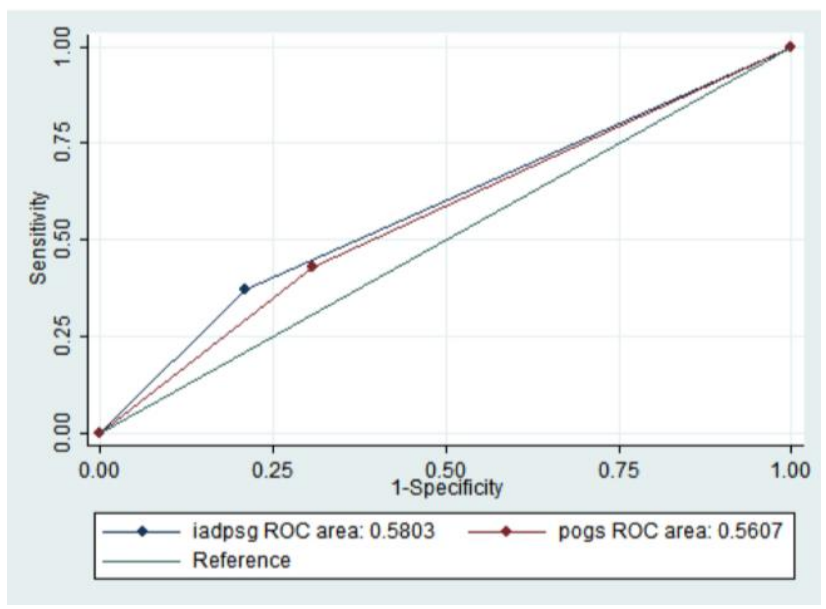

Figure 2. ROC for large for gestational age

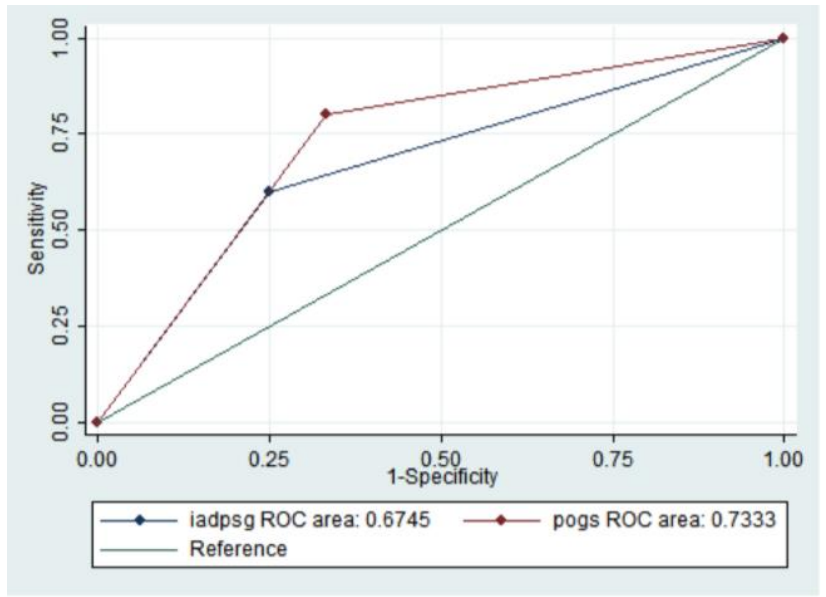

Figure 3. ROC for primary Caesarean section

\section{CONCLUSION}

Higher pre-gestational weight and advancing age were noted to be associated with GDM in our cohort of women, similar to that found in the study of Lim-Uy in $2010 .^{8}$ In another study, a pre-pregnancy weight above $190 \mathrm{lb}(86.4$ $\mathrm{kg}$ ) was a risk factor for the subsequent development of gestational diabetes mellitus. ${ }^{17}$

The risk for primary CS increased to 1.9 once diagnosed with GDM using the current cut-offs for diagnosis. This is similar to the findings of the HAPO trial. Unlike the trial, however, we did not find an increased risk for LGA among the infants of women in our cohort. One contributing factor may be the ethnic differences in the definition of LGA. Infants of Asian women may be significantly smaller than Caucasians, so that the use of the WHO curve, which was derived mainly from Caucasian cohorts, may underestimate the actual incidence of LGA birth weight. A study on racial differences of birth weight among term infants in Northern California noted that Asian and Hispanic infants had lower mean birth weights than white babies. ${ }^{18}$ Recently, birth weight curves tailored to maternal world region has been published by Ray in Canada. The study found that LGA may be missed in approximately 61 per 1000 male and 57 per 1000 female South Asian newborns if conventional rather than ethnicity-specific birth weight curves were used. ${ }^{19}$

Undergoing primary CS puts a woman at risk for subsequent multiple CS. This is then associated with complications such as placenta accreta, bowel or ureteral injury, blood transfusion, and ileus. ${ }^{20}$ It would be advisable to discuss the merits of a primary elective CS with GDM as the only indication, which was done in 4 women in our cohort (none in the non-GDM group). A large for gestational age fetus increases the risk of birth injury and dystocia, the primary reasons for recommending elective CS. There was no significant increase in the incidence of LGA in the study population.

A significant increase in the risk of infant admission to NICU was found in the GDM group, for various indications. This observation shows that aside from fetal macrosomia or LGA, offspring of women with GDM are also at risk for developing other morbidities that would necessitate NICU admission.

The comparison of outcomes between the group of GDM women that included those who were diagnosed with the POGS criteria and the group that excluded these women, showed no significant difference. This may signify that the higher thresholds of the IADPSG criteria adequately identified the women who were at risk for adverse perinatal outcomes. Utilizing lower thresholds may pose a burden to health resources; as such, the IADPSG cut-offs appear to be sufficient for our local setting.

The major limitation of this study is its retrospective nature, with a good number of patients excluded due to missing laboratory results and incomplete chart records. Some parameters, especially pre-pregnancy weights, were based largely on recall. A centralized laboratory for the performance of the $75 \mathrm{~g}$ OGTT would eliminate interlaboratory bias. The use of a region-specific curve for birth weights may give better estimates of the actual incidence of LGA for our setting. A prospective study will indeed be better powered to address these issues.

This study does provide new information about another important perinatal outcome in GDM. Other than LGA, infant admission to NICU was found to occur more frequently in our setting. This would require equal 
attention in future attempts to improve the provision of health care for Filipino women with GDM and their offspring.

The study also shows how a lower threshold for diagnosis in the form of a lower 2-hour OGTT cut-off does not significantly increase the frequency of adverse perinatal outcomes. A cost-utility analysis of the different strategies for screening and diagnosing gestational diabetes will also give practical insight on which strategy would be feasible for local adaptation.

\section{References}

1. Miller HC. The effect of diabetic and prediabetic pregnancies on the fetus and newborn infant. J Pediatrics. 1946;29(4):455-61. http://dx.doi.org/10.1016/S0022-3476(46)80164-1.

2. Litonjua A, Waspadji S, Pheng CS et al. AFES Study Group on Diabetes in Pregnancy: Preliminary data on prevalence. Philippine Journal of Internal Medicine. 1996;34(2):67-8.

3. Centers for Disease Control and Prevention. National diabetes fact sheet: National estimates and general information on diabetes and prediabetes in the United States, 2011. Atlanta, GA: U.S. Department of Health and Human Services, Centers for Disease Control and Prevention, 2011. http://www.cdc.gov/diabetes/pubs/pdf/ ndfs_2011.pdf.

4. Crowther C, Hiller J, Moss J, et al. Effect of treatment of gestational diabetes mellitus on pregnancy outcomes. $N$ Engl J Med. 2005;352(24):2477-86. http://dx.doi.org/10.1056/NEJMoa042973.

5. Landon MB, Spong CY, Thom E, et al. A multicenter, randomized trial of treatment for mild gestational diabetes. $\mathrm{N}$ Engl J Med. 2009;361(14):1339-48. http://dx.doi.org/10.1056/NEJMoa0902430.

6. Yuen GO, Layno I. Gestational diabetes mellitus: Incidence, maternal variables and perinatal outcomes among clinic patients of Cebu Doctorsoss J/pubs/pdf/ndfs_2011.pdfes and prediabetes. 1996;12(2):89-101.

7. Metzger BE, Lowe LP, Dyer AR et al. HAPO Study Cooperative Research Group. Hyperglycemia and adverse pregnancy outcomes. N Engl J Med. 2008;358(19):1991-2002. http://dx.doi.org/10.1056/ NEJMoa0707943.

8. Lim-Uy S, Cunanan E, Andag-Silva A. Prevalence and risk factors of gestational diabetes mellitus at the University of Santo Tomas Hospital. Philippine Journal of Internal Medicine. 2010;48(1):24-31.

9. Boney CM, Verma A, Tucker R, et al. Metabolic syndrome in childhood: Association with birth weight, maternal obesity and gestational diabetes mellitus. Pediatrics. 2005;115(3):e290-6.
10. Kim SY, England JL, Sharma JA, et al. Gestational diabetes mellitus and risk of childhood overweight and obesity in offspring: A systematic review. Experimental Diabetes Research 2011; Article ID 541308, 9 pages. http://dx.doi.org/10.1155/2011/541308.

11. Jimeno C., for the Technical Review Committee of the UNITE for DM Clinical Practice Guidelines on the Diagnosis and Management of Diabetes. A summary of the Philippines UNITE for diabetes clinical practice guidelines for the diagnosis and management of diabetes. Part I: Screening and diagnosis of DM. Journal of the ASEAN Federation of Endocrine Societies. 2011;26(1):26-30. http://dx.doi.org/10.15605/jafes.026.01.05.

12. Torres MV, Lagman-Dy P; for the Task Force on diabetes mellitus in pregnancy of the Philippine Obstetrical and Gynecological Society (Foundation), Inc. Clinical Practice Guidelines on Diabetes Mellitus in Pregnancy. 2nd edition. November 2011.

13. Pedula KL, Hillier TA, Schmidt MM, et al. Ethnic differences in gestational oral glucose screening in a large US population. Ethn Dis. 2009;19(4):414-9.

14. Silva JK, Ratner R, Kaholokula J, et al. Ethnic differences in perinatal outcome of gestational diabetes mellitus. Diabetes Care. 2006;29(9):2058-63. http://dx.doi.org/10.2337/dc06-0458.

15. Kurinczuk J, Hollowell J, Boyd PA, et al. Inequalities in infant mortality project briefing paper 4.The contribution of congenital anomalies to infant mortality. Oxford: National Perinatal Epidemiology Unit, 2010. http://www.npeu.ox.ac.uk/ downloads/files/infant-mortality/Infant-Mortality-Briefing-Paper4.pdf.

16. Maayan-Metzgerity A, Lubin D and Kuint J. Hypoglycemia rates in the first days of life among term infants born to diabetic mothers. Neonatology. 2009; 96(2):80-5. http://dx.doi.org/10.1159/000203337.

17. MacNeill S, Dodds L, Hamilton DC, et al. Rates and risk factors for recurrence of gestational diabetes. Diabetes Care. 2001;24(4):659-62. http://dx.doi.org/10.2337/diacare.24.4.659.

18. Madan A, Holland S, Humbert JE, et al. Racial differences in birth weight of term infants in a northern California population. J Perinatol. 2002;22(3):230-5. http://dx.doi.org/10.1038/sj.jp.7210703.

19. Ray JG, Sgro M, Mamdani MM et al. Birth weight curves tailored to maternal world region. J Obstet Gynaecol Can. 2012; 34(2):159-71.

20. Silver R, Landon M, Rouse D, et al. Maternal morbidity associated with multiple repeat Caesarean deliveries. Obstet Gynecol 2006;107(6):1226-32. http://dx.doi.org/10.1097/01.AOG. 0000219750.79480 .84 .

\footnotetext{
Articles and any other material published in the JAFES represent the work of the author(s) and should not be construed to reflect the opinions of the Editors or the Publisher. Authors are required to accomplish, sign and submit scanned copies of the JAFES Declaration: that the article represents original material, that is not being considered for publication or has not been published or accepted for publication elsewhere. Consent forms, as appropriate, have been secured for the publication of information about patients; otherwise, authors declared that all means have been exhausted for securing such consent. The authors have signed disclosures that there are no financial or other relationships that might lead to a conflict of interest. All authors are required to submit Authorship Certifications that the manuscript has been read and approved by all authors, and that the requirements for authorship have been met by each author.
} 